(2) Open Access Full Text Article

\title{
Repository corticotropin injection in patients with refractory psoriatic arthritis: a case series
}

This article was published in the following Dove Press journal:

Open Access Rheumatology: Research and Reviews

II November 2016

Number of times this article has been viewed

\author{
Alan N Brown \\ Low Country Rheumatology, North \\ Charleston, SC, USA
}

Purpose: Although numerous treatment options are available for patients with psoriatic arthritis (PsA), a need for effective and tolerable treatments remains for patients with refractory disease who have failed previous therapies and continue to experience tender and/or swollen joints, pain, and disease activity. Repository corticotropin injection (RCI) is believed to produce steroidogenic, steroid-independent, anti-inflammatory, and immunomodulatory effects in patients with rheumatic disorders, such as PsA. Limited literature exists on the use of RCI in patients with refractory PsA. The objective of this case series is to provide information on the clinical features of patients with refractory PsA and their response to RCI.

Patients: Nine patients treated with RCI for refractory PsA were retrospectively identified and included in the case series.

Results: All the nine patients experienced at least transient improvements in their active skin and joint disease. In some patients, it was necessary to titrate the RCI to an appropriate dose. RCI was used in some patients to bridge with another PsA therapy, such as apremilast or certolizumab. RCI was well tolerated, but discontinued in three patients due to preexisting conditions (hypertension and hyperglycemia).

Conclusion: RCI may be a safe and effective option for patients with refractory PsA who failed therapy with multiple previous treatments.

Keywords: treatment, adrenocorticotropic hormone, psoriatic arthritis biologic failures, melanocortin, refractory

\section{Introduction}

Psoriatic arthritis (PsA) is an inflammatory arthritis associated with psoriasis. ${ }^{1}$ It has been reported that about $30 \%$ of patients with psoriasis have a concomitant diagnosis of PsA. ${ }^{1,2}$ Along with skin involvement, PsA is characterized by pain, swelling, stiffness, and tenderness of the joints and surrounding ligaments and tendons. ${ }^{1}$

Diagnosis of PsA is based on clinical judgment; no specific serologic tests exist. ${ }^{3}$ Diagnosis is aided by the presence of joint inflammation, and psoriasis skin and nail lesions, paired with the absence of rheumatoid factor. ${ }^{3}$ The presentation of PsA is variable. PsA ranges from mild and non-destructive arthritis to a severe, debilitating disease. ${ }^{4}$

While the routine assessment of patient index data 3 (RAPID-3) is a validated assessment of rheumatoid conditions, thoughts regarding its use in patients with PsA vary. RAPID-3 is a patient-reported, composite index of three measures, physical function, pain, and patient global assessment, which can be quickly calculated. New research suggests that RAPID-3 may provide as much information about the progression of PsA as complex tests, which require laboratory results or formal joint count evaluations. ${ }^{5}$
Correspondence: Alan N Brown Low Country Rheumatology, 2860

Tricom Street, North Charleston, SC 29406-9333, USA

Tel +l 8435724840

Fax+l 8437936167

Email abrown@lowcountryrheumatology com 
Numerous treatment options are available for patients with PsA. ${ }^{6}$ Guidelines recommend the use of non-steroidal anti-inflammatory drugs, disease-modifying antirheumatic drugs (DMARDs), local and systemic glucocorticoids, tumor necrosis factor inhibitors, and other biologic agents. ${ }^{3,6}$ However, a need exists for effective and tolerable treatments for patients with refractory disease who have failed previous therapies and continue to experience tender and/or swollen joints, pain, and disease activity.

Repository corticotropin injection (RCI) is a long-acting formulation of the full sequence of adrenocorticotropic hormone (ACTH) (1-39). ${ }^{7}$ Melanocortin peptides, such as $\mathrm{ACTH}$, have been associated with both steroidogenic effects and steroid-independent, anti-inflammatory, and immunomodulatory effects. ${ }^{8}$ Melanocortins exert their effects through melanocortin receptors; there are currently five melanocortin receptors that have been identified. One receptor, $\mathrm{MC}_{2}$, is found in the adrenal cortex and is activated only upon engagement of ACTH. ${ }^{9}$ The result of activation of this receptor is an increase in steroidogenic enzyme expression and thus increased cortisol production. ${ }^{10}$ The remaining four melanocortin receptors, $\mathrm{MC}_{1}$, $\mathrm{MC}_{3}, \mathrm{MC}_{4}$, and $\mathrm{MC}_{5}$, are distributed among various tissues and exert distinct effects upon activation, which are collectively thought to contribute to the steroid-independent effects of melanocortins. ${ }^{9}$ In the immune system, activation of these receptors can result in modulation of the immune response by reducing pro-inflammatory transcription factor activation, ultimately decreasing the production of cytokines, chemokines, growth factors, and adhesion molecules. ${ }^{8,9}$ Melanocortin effects on rheumatic diseases were observed as early as 1949 in rheumatoid arthritis, with its efficacy in gouty arthritis and multiple sclerosis discovered later. ${ }^{11-13}$ Currently, RCI is US Food and Drug Administration (FDA)-approved formulation for use in several diseases, including PsA, multiple sclerosis, certain inflammatory ophthalmic diseases, and infantile spasms, among others. ${ }^{7}$ In addition to the stimulation of cortisol production, it is thought that RCI acts through direct action on melanocortin receptors and may counter pro-inflammatory signals and induce anti-inflammatory signals. ${ }^{9}$ Although RCI is FDA-approved for rheumatic disorders, limited literature exists on its use in patients with refractory PsA.

The nine patients reported in this case series received RCI based on its proposed unique mechanism of action after failing several previous therapies. This case series reports the clinical features of their PsA and response to RCI.

\section{Methods}

Nine patients with a history of PsA and treated with RCI (Mallinckrodt Pharmaceuticals, Hazelwood, MO, USA) for refractory PsA (defined as failure to achieve disease remission with previous treatment) were retrospectively identified and included in the case series. It was determined that Institutional Review Board approval was not required because this was not a clinical trial, no personal health information was divulged, and no patient treatment decisions were influenced based on the results of reporting this retrospective case series. Patients included in this case series provided consent for the use of their history.

\section{Results}

\section{Case I}

Case 1 is an 88-year-old female with a history of PsA for over 20 years. She failed golimumab and etanercept due to lack of efficacy, infliximab due to infusion reaction, adalimumab due to injection site reaction, and was unable to take methotrexate due to renal insufficiency. She had active joint disease, characterized by widespread arthralgias and joint tenderness, ankle swelling, elbow and thumb pain, and morning stiffness. She also had skin disease with small plaques present at her anterior hairline. Her high RAPID-3 score (20.7) indicated active disease.

She was prescribed RCI $80 \mathrm{U}$ twice a week (BIW) subcutaneously (SC). After 4 weeks of therapy, she experienced remarkable improvements in activities of daily life; she was able to sweep and do laundry. Her RAPID-3 score decreased to 14.3. She reported improvements the day after an RCI injection, but noted diminishing improvements until the next injection.

After 12 weeks of RCI $80 \mathrm{U}$ BIW, a maintenance dose of $20 \mathrm{U}$ thrice a week (TIW) SC was continued to decrease the time between dosing intervals. She continued to improve and her PsA was well-controlled. She had no impressive skin lesions; she had improved mobility, and only limited swelling in her fingers (may be related to osteoarthritis).

She continued doing well on RCI 20 U TIW SC for about 80 weeks; her PsA improved since starting RCI. Her skin was clear of any plaques or lesions; however, some unrelated hand and wrist pain remained unresolved (may be related to osteoarthritis). She tolerated RCI well throughout treatment and did not report any adverse events.

\section{Case 2}

Case 2 is a 46-year-old male with a 11/2-year history of PsA and hypertension. He had a family history of psoriasis and rheumatoid arthritis. He failed adalimumab and certolizumab in the past, due to lack of efficacy.

He had psoriatic plaques over the waistline and gluteal fold, as well as tender proximal interphalangeal (PIP) joints. His RAPID-3 score was 7.5. 
He was prescribed RCI 80 U BIW SC. After his third dose of RCI, he experienced remarkable improvement in joint pain and swelling. He stated that he was able to throw football with his son for the first time in 2 years. His skin disease "mostly cleared".

After approximately 12 weeks, his dose was lowered to RCI 40 U BIW SC, because he was responding well to 80 U BIW. His RAPID-3 score decreased slightly to 6.2. He believed the effect of RCI lasted for 48 hours after each dose, after which stiffness returned and his old skin lesions worsened. His dose was adjusted to RCI 20 U TIW SC. His dose was changed to help with the waning effect and because of weight gain $(\sim 4.5 \mathrm{~kg})$ and worsening of existing, untreated hypertension.

While on RCI, he noted improvements in joint pain and skin lesions, and reported no joint swelling. However RCI was discontinued after 6 months, due to worsening existing hypertension and weight gain.

\section{Case 3}

Case 3 is a 51-year-old female with a 5-year history of PsA. She failed certolizumab and adalimumab due to lack of efficacy and infliximab due to infusion reactions.

She had active PsA characterized by inflammation in her fingers, joint pain, and skin disease. She noted pain in her shoulders when putting on her work uniform. Her RAPID-3 score was 9.7.

She was prescribed RCI 80 U BIW SC. After four injections, she noted improvements in skin and joint disease. She experienced minimal joint pain, no joint swelling or morning stiffness, and her skin disease markedly improved.

After 8 weeks of RCI, her RAPID-3 score decreased to 3.0, resulting in reported improvements in symptoms. Her skin improved and joint disease essentially resolved. She experienced elevated blood pressure and gained 10 pounds, but continued RCI for another 4 weeks.

After responding well to a 12-week course of RCI, she was prescribed alternative therapy for her PsA.

\section{Case 4}

Case 4 is a 55-year-old female with a 71/2-year history of PsA. She failed etanercept, golimumab, infliximab, and adalimumab due to lack of efficacy and stopped methotrexate (she believed it was responsible for her anemia).

She experienced pain in her feet, knees, and hands. Her erythrocyte sedimentation rate (ESR) $(49 \mathrm{~mm} / \mathrm{h})$ and C-reactive protein (CRP) $(1.95 \mathrm{mg} / \mathrm{dL})$ were elevated, indicating active joint disease. Her RAPID-3 score was 19.3. She did not have any remarkable skin lesions.

She was prescribed RCI 80 U BIW SC. She noted improvements after the first injection. After 4 weeks on RCI, she had notable improvement in joint pain and stiffness. Her ESR decreased to $16 \mathrm{~mm} / \mathrm{h}$ and CRP to $0.94 \mathrm{mg} / \mathrm{dL}$. After 8 weeks of treatment, her RAPID-3 score decreased to 3 .

She continued to improve throughout the RCI course, noting no pain, swelling, or morning stiffness, with the exception of her right index finger.

She responded well, did not report any adverse events, completed her course of RCI, and was prescribed a different course of treatment for her PsA.

\section{Case 5}

Case 5 is a 58-year-old male with an 8-year history of PsA and hypertension. He failed adalimumab and certolizumab due to lack of efficacy.

He experienced widespread arthralgia and neck pain, as well as active skin disease, with widespread psoriatic plaques on his face, ears, elbows, and knees. His RAPID-3 score was 8.3.

He was prescribed RCI 80 U BIW SC. His skin disease and arthralgia were markedly improved after 1 month of RCI, having limited plaque involvement in the affected areas and no joint swelling.

RCI was well tolerated and discontinued after the 12-week course to bridge treatment with apremilast. After 12 weeks of RCI, his RAPID-3 score decreased to 6 .

\section{Case 6}

Case 6 is a 66-year-old female with a 5-year history of PsA. She failed methotrexate, adalimumab, and ustekinumab due to lack of efficacy.

She had severe skin flares over her palms and soles with pustular lesions, and cracked, bleeding, and painful skin on the palms and soles of her hands and feet. The joint disease in her hands also flared and she had swollen PIP joints. Her ESR and CRP were elevated at $61 \mathrm{~mm} / \mathrm{h}$ and $1.3 \mathrm{mg} / \mathrm{dL}$, respectively, indicating active disease.

She was prescribed RCI 80 U BIW SC and showed marked improvements in joint and skin disease 6 weeks post initial RCI dose. She no longer experienced bleeding from skin plaques, joint pain, swelling, or stiffness.

She had a great amount of energy on RCI and stated that she could perform yardwork. Due to her remarkable response with RCI, after 12 weeks, the dose was reduced to 40 U BIW SC. 
After 24 weeks and continued improvements, the dose of RCI was further decreased to $20 \mathrm{U}$ BIW; she still reported no joint pain, swelling, or stiffness. Her ESR and CRP decreased to $45 \mathrm{~mm} / \mathrm{h}$ and $0.6 \mathrm{mg} / \mathrm{dL}$, respectively. However, her skin disease was more active on lower doses of RCI; she had erythema and scaling over palms and soles.

She reported experiencing facial flushing the day after RCI dose, which resolved after about 6 hours. She also experienced worsening of preexisting hyperglycemia once RCI was started. Her primary care physician prescribed metformin and glipizide, but her fasting blood glucose levels remained elevated on the afternoon of the RCI dose; therefore, after 30 weeks, RCI was discontinued.

\section{Case 7}

Case 7 is a 37-year-old male with a 2-year history of PsA. He failed adalimumab in the past, due to lack of efficacy.

He had active skin disease, with skin lesions over his penis, soles of feet, and right ear, as well as a small effusion and left knee monoarthritis. His RAPID-3 score was 4.

He was prescribed RCI 80 U BIW SC. After 6 weeks of $\mathrm{RCI}$, he experienced marked improvements in both joint and skin disease. He had no knee pain and had improvements in range of motion; however, skin lesions were present.

After 3 months of RCI, he reported no joint pain or swelling, but limited continued improvement of lesions on his feet and penis. His RAPID-3 score decreased to 2.8 and RCI was discontinued. Although RCI was well tolerated and his joints improved, his skin disease only improved transiently and relapsed over time.

\section{Case 8}

Case 8 is a 69-year-old female with a 7-year history of PsA. She failed adalimumab, methotrexate, and certolizumab monotherapy due to lack of efficacy.

She had active joint disease and complained of hip and left shoulder pain. Her psoriasis worsened, with psoriatic plaques over her lower left extremities, abdomen, back, and posterior ears.

She was prescribed RCI $80 \mathrm{U}$ BIW SC, in addition to certolizumab $400 \mathrm{mg}$ SC every 2 weeks. After seven doses of $\mathrm{RCI}$, she noted improvements in joint pain and skin lesions on her lower left extremity, abdomen, and back.

RCI was well tolerated and discontinued after a 12-week course, as she responded well. Certolizumab was continued alone. RCI was used to successfully bridge ongoing therapy with certolizumab.

\section{Case 9}

Case 9 is a 48-year-old female with a 19-year history of PsA. She failed adalimumab and certolizumab due to lack of efficacy.

She had active skin disease characterized by psoriatic plaques posterior to the ear, over the left elbow, and over lower extremities. She also noted morning stiffness for 2 hours.

She was prescribed RCI 80 U BIW SC and noted remarkable skin and joint improvements after 2 weeks of treatment. Her plaques were thinner and not as erythematous, and her morning stiffness decreased to 10 minutes.

After 3 months on RCI, her joint pain, swelling, and morning stiffness resolved completely for 2 days after an injection, then returned on day 3. While RCI was well tolerated, her skin disease did not improve much in the last few weeks of treatment and as such, RCI was discontinued.

\section{Conclusion}

In this case series, all patients had previously failed treatment with up to five DMARDs and/or biologic agents or were contraindicated for alternate DMARDs or biologics (Table 1). RCI was prescribed due to its mechanism of action, which may provide unique anti-inflammatory and immunomodulatory effects beyond steroidogenesis. ${ }^{\text {? }}$

RCI provided improvements for most patients, with more patients experiencing joint improvements than skin improvements. While some patients only had temporary relief of their joint pain or skin lesions, other patients experienced longer relief. One patient was on RCI maintenance for over 80 weeks. In some patients RCI was used to bridge patients' PsA therapy with other medications, such as apremilast or certolizumab.

Overall, RCI was well tolerated, but discontinued in three patients due to worsening preexisting conditions. Through its steroidogenic effect and glucocorticoid-dependent antiinflammatory action, RCI is associated with hyperglycemia and weight gain. These side effects are similar to those seen with corticosteroids. ${ }^{9}$

Results from this case series suggest that RCI may be a safe and effective option for patients with refractory PsA who failed therapy with multiple previous treatments.

\section{Acknowledgments}

The author is grateful to Dunay Worth for her assistance and to Dr Danielle Cavazzini of AXON Communications for writing assistance in the development of this manuscript. Funding to support the preparation of this manuscript was provided by Autoimmune and Rare Diseases Business, Mallinckrodt Pharmaceuticals. 
Table I Patient characteristics, previous treatments, and $\mathrm{RCl}$ response

\begin{tabular}{|c|c|c|c|c|}
\hline Case & Age (years) & Gender & Previous treatment failures & $\mathrm{RCl}$ response \\
\hline $\mathrm{I}$ & 88 & $\mathrm{~F}$ & $\begin{array}{l}\text { Golimumab and etanercept due to lack of } \\
\text { efficacy, infliximab due to infusion reaction, } \\
\text { adalimumab due to injection site reaction, } \\
\text { and cannot take methotrexate (renal } \\
\text { insufficiency) }\end{array}$ & $\begin{array}{l}\text { - Patient noted both skin and joint improvements on } \mathrm{RCl} \\
\text { - Patient responded better to a thrice a week dosing regimen, } \\
\text { which offered fewer days between doses } \\
\text { - After approximately } \mathrm{I.5} \text { years on } \mathrm{RCl} \text {, the patient noted a gradual } \\
\text { decrease in her ability to carry out activities of daily life; however, } \\
\text { this could be a result of natural aging } \\
\text { - Patient tolerated } \mathrm{RCl} \text { well }\end{array}$ \\
\hline 2 & 46 & M & $\begin{array}{l}\text { Adalimumab and certolizumab due to } \\
\text { lack of efficacy }\end{array}$ & $\begin{array}{l}\text { - Patient experienced remarkable improvements in skin and joint } \\
\text { disease while on } \mathrm{RCl} \\
\text { - Able to throw football with son for first time in } 2 \text { years } \\
\text { - Over time, effect of } \mathrm{RCl} \text { did not seem to be as marked } \\
\text { - } \mathrm{RCl} \text { was discontinued due to worsening preexisting hypertension } \\
\text { and weight gain }\end{array}$ \\
\hline 3 & 51 & $\mathrm{~F}$ & $\begin{array}{l}\text { Certolizumab and adalimumab, due to lack } \\
\text { of efficacy and infliximab due to infusion } \\
\text { reactions }\end{array}$ & $\begin{array}{l}\text { - Patient's skin improved and joint disease essentially resolved with } \\
\mathrm{RCl} \\
\text { - } \mathrm{RCl} \text { was discontinued due to elevated blood pressure and weight } \\
\text { gain }\end{array}$ \\
\hline 4 & 55 & $\mathrm{~F}$ & $\begin{array}{l}\text { Etanercept, golimumab, infliximab, and } \\
\text { adalimumab and stopped taking } \\
\text { methotrexate (believed it was responsible } \\
\text { for low hemoglobin levels) }\end{array}$ & $\begin{array}{l}\text { - Patient had remarkable improvements in joint pain and stiffness } \\
\text { - } \mathrm{RCl} \text { was discontinued due to unrelated illness } \\
\text { - Patient tolerated } \mathrm{RCl} \text { well }\end{array}$ \\
\hline 5 & 58 & M & $\begin{array}{l}\text { Adalimumab and certolizumab due to } \\
\text { lack of efficacy }\end{array}$ & $\begin{array}{l}\text { - Patient noted marked joint improvements on } \mathrm{RCl} \\
\text { - Skin disease also improved but did not clear } \\
\text { - RCl was used to transition therapy to apremilast } \\
\text { - Patient tolerated } \mathrm{RCl} \text { well }\end{array}$ \\
\hline 6 & 66 & $\mathrm{~F}$ & $\begin{array}{l}\text { Methotrexate, adalimumab, and } \\
\text { ustekinumab due to lack of efficacy }\end{array}$ & $\begin{array}{l}\text { - Patient's skin and joint disease greatly improved on } \mathrm{RCl} \\
\text { - Patient had great amount of energy and was able to do } \\
\text { yardwork } \\
\text { - RCl was discontinued due to worsening hyperglycemia }\end{array}$ \\
\hline 7 & 37 & M & Adalimumab due to lack of efficacy & $\begin{array}{l}\text { - Patient experienced marked initial improvements in joint and skin } \\
\text { disease on } \mathrm{RCl} \\
\text { - After } 3 \text { months of } \mathrm{RCl} \text {, patient noted continued improvements in } \\
\text { joint pain; however, his skin disease worsened } \\
\text { - RCl was discontinued due to lack of skin improvement } \\
\text { - Patient tolerated } \mathrm{RCl} \text { well }\end{array}$ \\
\hline 8 & 69 & $\mathrm{~F}$ & $\begin{array}{l}\text { Adalimumab, methotrexate, and } \\
\text { certolizumab monotherapy due to lack of } \\
\text { efficacy }\end{array}$ & $\begin{array}{l}\text { - Patient experienced improvements in both skin and joint disease } \\
\text { on } \mathrm{RCl} \\
\text { - } \mathrm{RCl} \text { was used to successfully bridge ongoing therapy with } \\
\text { certolizumab } \\
\text { - Patient tolerated } \mathrm{RCl} \text { well }\end{array}$ \\
\hline 9 & 48 & $\mathrm{~F}$ & $\begin{array}{l}\text { Adalimumab and certolizumab due to } \\
\text { lack of efficacy }\end{array}$ & $\begin{array}{l}\text { - Patient had initial skin and joint improvements on } \mathrm{RCl} \\
\text { - After a I2-week course of } \mathrm{RCl} \text {, the patient reported temporary } \\
\text { joint improvements and did not have significant skin disease } \\
\text { improvements } \\
\text { - } \mathrm{RCl} \text { was discontinued } \\
\text { - Patient tolerated } \mathrm{RCl} \text { well }\end{array}$ \\
\hline
\end{tabular}

Abbreviations: $\mathrm{F}$, female; $\mathrm{M}$, male; $\mathrm{RCl}$, repository corticotropin injection.

\section{Disclosure}

Alan N Brown is a member of the speaker bureau for Abbvie and Mallinckrodt. The author reports no other conflicts of interest in this work.

\section{References}

1. Gladman D, Antoni C, Mease P, Clegg D, Nash P. Psoriatic arthritis: epidemiology, clinical features, course, and outcome. Ann Rheum Dis. 2005;64(Suppl 2):ii14-ii17.
2. Zachariae H, Zachariae R, Blomqvist K, Davidsson S, Molin L, Mørk C, Sigurgeirsson B. Quality of life and prevalence of arthritis reported by 5,795 members of the Nordic Psoriasis Associations. Data from the Nordic Quality of Life Study. Acta Derm Venereol. 2002;82(2): 108-113.

3. Gottlieb A, Korman NJ, Gordon KB, et al. Guidelines of care for the management of psoriasis and psoriatic arthritis: section 2. Psoriatic arthritis: overview and guidelines of care for treatment with an emphasis on the biologics. J Am Acad Dermatol. 2008;58(5):851-864.

4. Lloyd P, Ryan C, Menter A. Psoriatic arthritis: an update. Arthritis. 2012;2012:176298. 
5. Reddy SM, Scher JU, Szumski A, Hsu MA, Marshall H, Jones H, Yazici Y. SAT0584 Comparative performance of Rapid 3 (routine assessment of patient index data 3 ) versus other composite indices in clinical trials of psoriatic arthritis. Ann Rheum Dis. 2015;74(Suppl 2):872.

6. Gossec L, Smolen JS, Gaujoux-Viala C, et al. European league against rheumatism recommendations for the management of psoriatic arthritis with pharmacological therapies. Ann Rheum Dis. 2012;71(1):4-12.

7. H.P. Acthar $\mathrm{Gel}^{\circledR}$ (repository corticotropin injection) [prescribing information]. Hazelwood MO: Mallinckrodt Pharmaceuticals, Inc; 2015.

8. Catania A, Lonati C, Sordi A, Carlin A, Leonardi P, Gatti S. The melanocortin system in control of inflammation. ScientificWorldJournal. 2010;10:1840-1853.
9. Montero-Melendez T. ACTH: the forgotten therapy. Semin Immunol. 2015;27(3):216-226.

10. Xing Y, Parker CR, Edwards M, Rainev WE. ACTH is a potent regulator of gene expression in human adrenal cells. J Mol Endo. 2010;45(1):59-68.

11. Hench PS, Kendal EC, Slocumb CH, et al. The effect of a hormone of the adrenal cortex (17-hydroxy-11-dehydrocorticosterone compound E) and of pituitary adrenocorticotropic hormone on rheumatoid arthritis. Ann Rheum Dis. 1949;24(8):181-197.

12. Gutman AB, Yu TF. Effects of adrenocorticotropic hormone (ACTH) in gout. Am J Med. 1950;9(1):24-30.

13. Miller H, Newell DJ, Ridley A. Multiple sclerosis treatment of acute exacerbations with corticotrophin (ACTH). Lancet. 1961;278(7212): $1120-1122$.

\section{Publish your work in this journal}

Open Access Rheumatology: Research and Reviews is an international, peerreviewed, open access journal publishing original research, reports, editorials, reviews and commentaries on all aspects of clinical and experimental rheumatology in the clinic and laboratory including the following topics: Pathology, pathophysiology of rheumatological diseases; Investigation, treatment and management of rheumatological diseases; Clinical trials and novel pharmacologi$\mathrm{cal}$ approaches for the treatment of rheumatological disorders. The manuscrip management system is completely online and includes a very quick and fair peer-review system, which is all easy to use. Visit http://www.dovepress.com testimonials.php to read real quotes from published authors. 